\title{
Does administration of non-steroidal anti-inflammatory drug determine morphological changes in adrenal cortex: ultrastructural studies
}

\author{
Włodzimierz Matysiak • Barbara Jodłowska-Jędrych
}

Received: 10 March 2010/Accepted: 28 July 2010 / Published online: 19 August 2010

(C) The Author(s) 2010. This article is published with open access at Springerlink.com

\begin{abstract}
Rofecoxib (Vioxx $\bigodot$ made by Merck Sharp \& Dohme, the USA) is a non-steroidal anti-inflammatory drug which belongs to the group of selective inhibitors of cyclooxygenasis-2, i.e., coxibs. Rofecoxib was first registered in the USA, in May 1999. Since then the drug was received by millions of patients. Drugs of this group were expected to exhibit increased therapeutic action. Additionally, there were expectations concerning possibilities of their application, at least as auxiliary drugs, in neoplastic therpy due to intensifying of apoptosis. In connection with the withdrawal of Vioxx ( (rofecoxib) from pharmaceutical market, attempts were made to conduct electron-microscopic evaluation of cortical part of the adrenal gland in preparations obtained from animals under influence of the drug. Every morning animals from the experimental group (15 rats) received rofecoxib (suspension in physiological saline) - non-steroidal anti-inflammatory drug (Vioxx@), Merck Sharp and Dohme, the USA), through an intragastric tube in the dose of $1.25 \mathrm{mg}$ during 8 weeks. In the evaluated material, there was found a greater number of secretory vacuoles and large, containing cholesterol and other lipids as well as generated glucocorticoids, lipid drops in cytoplasm containing prominent endoplasmic reticulum. There were also found cells with cytoplasm of smaller densityespecially in apical and basal parts of cells. Mitochondria occasionally demonstrated features of delicate swelling. The observed changes, which occurred on cellular level with application of large doses of the drug, result from mobilization of adaptation mechanisms of the organism.
\end{abstract}

W. Matysiak · B. Jodłowska-Jędrych $(\bowtie)$

Department of Histology and Embryology,

Medical University of Lublin, 11 Street Radziwiłłowska,

20-080 Lublin, Poland

e-mail: b.jedrychj@gmail.com

W. Matysiak

e-mail: w.matysiak@wp.pl
Keywords Adrenal cortex - Zona fasciculata .

Ultrastructure $\cdot$ Coxibs $\cdot$ Vioxx (

$\begin{array}{ll}\text { Abbreviations } \\ \text { ACTH } & \text { Adrenocorticotropic hormone } \\ \text { ALAT } & \text { Alanine amino transferase } \\ \text { APROV } & \text { Adenomatous polyp prevention on Vioxx } \\ \text { ASPAT } & \text { Aspargin amino transferase } \\ \text { COX } & \text { Cyclooxygenase } \\ \text { COX-1 } & \text { Cyclooxygenase-1 } \\ \text { COX-2 } & \text { Cyclooxygenase-2 } \\ \text { GRE } & \text { Glucocorticoid response elements } \\ \text { IL } & \text { Interleukin } \\ \text { IL-1 } \beta & \text { Interleukin-1 } \beta \\ \text { LPS } & \text { Lipopolysaccharide } \\ \text { NFkB } & \text { Nuclear factor kB } \\ \text { NF-IL-6 } & \text { Nuclear factor IL-6 } \\ \text { NP } & \text { Sodium nitroprusside } \\ \text { NSAID } & \text { Non-steroidal anti-inflammatory drugs } \\ \text { PGs } & \text { Prostaglandins } \\ \text { PGE } 2 & \text { Prostaglandin E } 2 \\ \text { SER } & \text { Smooth endoplasmic reticulum } \\ \text { TNF } \alpha & \text { Tumor necrosis factor } \alpha \\ \text { TLR-2 } & \text { Toll-like receptor } 2 \\ \text { TLR-4 } & \text { Toll-like receptor } 4 \\ \text { VIGOR } & \text { Vioxx Gastrointestinal Outcomes Research }\end{array}$

\section{Introduction}

Non-steroidal anti-inflammatory drugs are a group of commonly used medications which show anti-inflammatory, analgesic, and antipyretic action (Huang 2000; Crofford 2001; Courtney and Doherty 2002; Spiegel et al. 2003; 
Price-Forbes et al. 2005; Dickman and Ellershaw 2004; Ong et al. 2007; Ramirez-Alcantara et al. 2009).

At the beginning of the 1990 s the discovery of cyclooxygenase isoforms enabled a better understanding of inflammation pathomechanism, which led to the creation of a new class of drugs, namely coxibs. They display antiinflammatory action comparable to the classic non-steroidal anti-inflammatory drugs, with minimal adverse effects (Vane et al. 1990; Huang 2000; Luo et al. 2005).

Until the beginning of the 1990s only one enzyme of cyclooxygenase activity had been believed to exist. At that time there was observed a considerable increase in cyclooxygenase protein concentration in experimental conditions. In 1990 (Masferrer et al. 1990), discovered an increase in cyclooxygenase protein concentration in peritoneal macrophages of mice, in which an inflammatory condition was induced by intravenous administration of bacterial lipopolysaccharide. That increase was inhibited by corticosteroids. In the same year, Fu et al. (1990) proved cyclooxygenase protein induction in human monocytes. In 1989, while studying neoplastic transformation of domestic chicken embryo fibroblasts infected with Rous sarcoma, Simmons et al. (1989) discovered an increase in the concentration of several, different sequences of mRNA. Further investigations (Bakhle 1999) revealed that one of those sequences codes for an enzyme of cyclooxygenase activity.

The studies of Needleman and Manning (1999) and Simmons et al. (2004) contributed to the discovery of the existence of two isoforms of cyclooxygenase cyclooxygenase (COX)-1 and COX-2. The next years brought along synthesizing and introducing of selective inhibitors COX-2 into treatment. Those drugs show effective anti-inflammatory action and incomparably smaller adverse effects in relation to non-selective drugs (Lipsky et al. 2000).

In normal conditions, COX-2 expression is practically undetectable in most tissues, and it increases several times after stimulation. In vitro an increase in gene expression for COX-2 was discovered, e.g., after stimulation of cells with: cytokines (IL-1 $\beta, \mathrm{TNF}-\alpha$ ), mitogens, phorbol esters, serum, and tetracycline (Connel et al. 1994; Ichitani et al. 2001). The gene activity is inhibited by corticosteroids Il-4 and Il-10 (Tominaga et al. 1991; Weber et al. 1997). Apart from reducing of gene expression, corticosteroids decrease the stability of mRNA for COX-2. In vivo an increase in enzyme expression and level of COX-2 protein was discovered in bioptic material from inflamed tissues of air passages, skin, alimentary tract and many other organs.

Both isoforms also differ in intracellular location. The activity of COX-1 is mainly located in the vicinity of endoplasmic reticulum, whereas COX-2 mainly occurs in the area of external nuclear membrane (Gierse et al. 1996; Whittle 2000).
Apart from its direct participation in the process of prostaglandin synthesis, COX-1 also affects the production of gastric juice, and thus was responsible for chronic inflammation of stomach mucous membranes in longer administration of drugs blocking that enzyme (Langman et al. 1999; Warner and Mitchell 2004). COX-2 is only engaged in the process of prostaglandin synthesis (Price-Forbes et al. 2005). COX-2 seemed to be an ideal target for non-steroidal anti-inflammatory drugs (NSAID). This beneficially resulted in the introduction of COX-2 selective inhibitors into medical practice in the late 1990s. Rofecoxib (Vioxx), Celecoxib (Celebrex), Valdecoxib (Bextra), Etericoxib (Arcoxia) (Fig. 1) soon achieved a strong position in the pharmaceutical market (Kawamori et al. 1998; Malmstrom et al. 1999; Steinbach et al. 2000; Dannhardt and Kiefer 2001; Zarraga and Schwarz 2007). The appearance of those drugs, which undoubtedly gave new and promising prospects in medical care, was enthusiastically considered a breakthrough in the therapy of pain and inflammatory processes (Mandell 1999).

Rofecoxib (marketed under the brand name of Vioxx), i.e., 4-(4-methylsulfonylphenyl)-3-phenyl-5H-furan, is nonsteroidal anti-inflammatory drug from the group of diphenylfuran. It shows anti-inflammatory, analgesic, and antipyretic actions (Ehrich et al. 1999). It was mainly used in the treatment of acute and chronic phase of degenerative joint disease, and also in osteoporosis as an analgesic agent. It inhibits the activity of COX-2 approximately 800 times more strongly than COX-1 activity, affecting the arrest of synthesis of prostaglandins induced during inflammatory process (Hellstrom 2007). Rofecoxib is administered in the

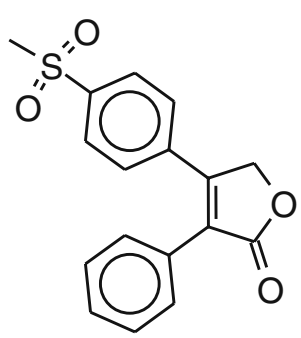

Rofecoxib, Vioxx<smiles>Cc1onc(-c2ccc(S(N)(=O)=O)cc2)c1-c1ccccc1</smiles>

Valdecoxib, Bextra<smiles>Cc1ccc(-c2cc(C(F)(F)F)nn2-c2ccc(S(N)(=O)=O)cc2)cc1</smiles>

Celecoxib, Celebrex<smiles>Cc1ccc(-c2ncc(Cl)cc2-c2ccc(S(C)(=O)=O)cc2)cn1</smiles>

Etorcoxib, Arcoxia
Fig. 1 Structural formulas of selective inhibitors COX 
therapeutic doses of $12.5,25$, or $50 \mathrm{mg}$, and available in the form of tablets or suspension. The drug is almost completely absorbed (approximately 93\%) from the alimentary track. The maximum concentration in plasma occurs after approximately $3 \mathrm{~h}$ and amounts to $0.305 \mathrm{mg} / 1$ in stationary condition. When the drug is administered together with food, its maximum concentration is after approximately 4-5 h, but the total amount of absorbed drug, its maximum concentration or biological availability do not change (Scali et al. 2003). However, simultaneous administration of drugs neutralizing hydrochloric acid decreases its absorption. Rofecoxib is metabolized in the liver by cytosol enzymes. The main pathway of metabolism is reduction of the drug to cis-dihydro-derivatives and trans-dihydro-derivatives of rofecoxib, which do not show any reaction to cyclooxygenase activity. Cytochrome P-450 plays only a small role in rofecoxib metabolism. Through its action the drug is transformed into hydroxylic derivative which is then combined with glucuronic acid. In this way $9 \%$ of the drug is metabolized, consequently inhibiting of cytochrome activity has practically no effect on the drug kinetics (Scali et al. 2003).

Apart from the side effects typical of NSAID, such as alimentary track disorders (nausea, vomiting, abdominal pains), impairment of liver functions (liver failure and inflammation) may also occur. In the kidneys adverse effects are connected with inhibiting of $\mathrm{E}_{2}\left(\mathrm{PGE}_{2}\right)$ and $\mathrm{E}_{2}$ $\left(\mathrm{PGE}_{2}\right)$ prostaglandins synthesis by rofecoxib (Mohn et al. 2005). These compounds are responsible for regulating of secretion and absorption of sodium and potassium ions. Decrease in prostaglandins concentration due to the use of Vioxx preparation contributes to the occurrence of numerous kidney diseases such as renal failure, ischaemia and inflammatory conditions (Fletcher et al. 2006). Disorders in sodium-potassium balance on renal level have consequences affecting the whole organism, and cause hyperkalemia, retention of water in the organism and occurrence of oedema. Rofecoxib also affects the occurrence of thrombotic-embolic episodes. In patients using rofecoxib there was also observed an increase in the activity of liver enzymes ALAT, ASPAT, and decrease in hematocrit value, the number of erythrocytes, hemoglobin and leucocytes. However, the activity of alkaline phosphatase, levels of urea and creatinine rise during treatment with the drug (Hawkey 1999).

Vioxx was introduced into the pharmaceutical market in 1999, approved by Food and Drug Administration (FDA).

Even before the drug launch there had appeared first information about its toxicity. Vioxx considerably reduced the risk of bleeding and ulceration of the alimentary track. This one-sided emphasizing of the lack of gastrological toxicity while ignoring other unfavorable cases was the cause of introducing of Vioxx into the market based on VIGOR study. The assumption of that study (Bombardier et al. 2000) was to prove the drug safety in the aspect of complications in the alimentary track. At the same time the study revealed that the drug increases the risk of myocardial infarction five times. The justification that a myocardial infarction which developed in the period of time shorter than 18 months after the use of rofecoxib had not been caused by the drug also proved to be faulty.

The study which turned out to decide about the future of rofecoxib was APROV study (Głuszko 2004), which was to evaluate rofecoxib effectiveness in the treatment of large intestine polyps in patients with diagnosed adenomas of large intestine. The study was interrupted immediately after there had been detected an increased risk of thrombus, cardiac infarction and cerebral stroke occurrence in the group receiving rofecoxib.

In 2004, Merck Sharp \& Dohme (MSD) company withdrew Vioxx (rofecoxib) drug, which was then available in 80 countries in the world and used in the treatment of pain in the course of rheumatic diseases. The company's decision was affected by the results of clinical trials which revealed an increased risk of cardiac-vascular incidents in patients receiving that drug (Kim et al. 2004; Lenzer 2005; Thomas 2006; Wadman 2007; Haag et al. 2008; Krumholz et al. 2008; Roumie et al. 2008).

\section{Materials and methods}

The study was conducted on male white rats of Wistar strain, with body mass of 300-350 g, which stayed in the same conditions and received standard diet and drinking water ad libitum during the experiment.

The control group consisted of animals (ten rats) which did not receive any other substance except standard granulated fodder and drinking water.

Every morning the animals from the experimental group (15 rats) received rofecoxib (suspension in physiological saline) - a non-steroidal anti-inflammatory drug (Vioxx ( preparation, Merck Sharp and Dohme, the USA), through an intragastric tube in the dose of $1.25 \mathrm{mg}$ during 8 weeks.

After finishing of the experiment cycle the rats were decapitated and sections including the cortical part (zona fasciculata) of the adrenal gland were obtained for ultrastructural examination.

The sections of the cortical part of the adrenal glands were fixed for $2 \mathrm{~h}$ in the solution of glutaraldehyde in phosphate buffer with $\mathrm{pH}$ 7.2. The material was further fixed in $1 \%$ solution of $\mathrm{OsO}_{4}$, dehydrated in a series of alcohols with rising concentration and embedded in Durcupan resin (ACM Fluka). The blocks were polymerized at the temperature of $60^{\circ} \mathrm{C}$, then cut by means of ultramicrotom cutter made by Reichert company. Ultrathin sections were contrasted using uranyl acetate and lead 
citrate (Reynolds 1963). They were watched and photographed using an electron microscope Tesla BS 500.

The study results were analyzed statistically. The values of the analyzed measurable parameters were characterized using mean value and standard deviation. Due to the skewed distribution of the studied parameters evaluated by means of the Shapiro-Wilk test or heterogeneity of variances evaluated by the F-test, the Mann-Whitney $U$ test was used to analyze the differences between the studied subgroups. There was assumed 5\% inference error and the differences were considered statistically significant when $p<0.05$. The statistical analyses were conducted using STATISTICA v. 8.0 (StatSoft, Polska).

\section{Results}

Electron microscopy

\section{Control group}

In the examined preparations obtained from the control group animals the ultrastructural images of the adrenal cortex zona fasciculata cells were normal (Fig. 3).

Large cell sizes and considerable abundance of organelles were particularly noticeable. The cells were dominated by round nuclei, the largest of the cell nuclei from all the adrenal cortex zones. Electron-dense heterochromatin created irregular clusters, mainly situated near the nuclear envelope, where nucleopores could be spotted. In the nucleus located in the central part of large polygonal (cubic) cells there were electron dense 1 or 2 nucleoli of irregular shape.

The electron microscope showed a well-developed smooth endoplasmic reticulum and the Golgi apparatus located close to the nucleus, on the pericapillary side. Mitochondria were more numerous than in the zona glomerulosa cells, more oval in shape and contained, almost exclusively, tubular and vesicular cristae. The mitochondrial matrix was electron lucent. Apart from typical cytoplasmic structures there occurred lysosomes containing crystal structures. Lumina of numerous capillary vessels were visible. On the side of the capillary the cell wall contained microvilli, which sometimes perforated the basement membrane of the glandular epithelium and contacted the pericapillary space.

\section{Experimental group}

In the studied material from the experimental group of animals there were visible all the cellular organelles: the cell nucleus with 1 or 2 nucleoli, rough and smooth endoplasmic reticula, secretory vacuoles and lipid drops, the Golgi structures, mitochondria, lysosomes.
The zona fasciculata glandular cells were heterogenous, some of them contained nuclei with dense chromatin, the others, however, had nuclei with rare chromatin. The proportions of euchromatin to heterochromatin occurrence were similar to the control group image. There could be seen a well-developed endoplasmic reticulum with single ribosomes, and also polyribosomes lying in groups, which had contact with the external membranes of the endoplasmic reticulum. The Golgi apparatus was less visible than in the control group images. In its structure, the following elements could be identified: cisternae (dictyosomes), flattened in the central part and widened in the peripheral part, numerous vesicles, and large vacuoles containing non-structural or granular material. What is important, as a result of the conducted experiment, in the cytoplasm with prominent endoplasmic reticulum there was found (Fig. 2a, b) a greater number of secretory vacuoles, a considerable increase in the number of lipid drops containing cholesterol, other types of lipids and generated glucocorticoids, as compared with the preparations from the control group animals. There were also observed
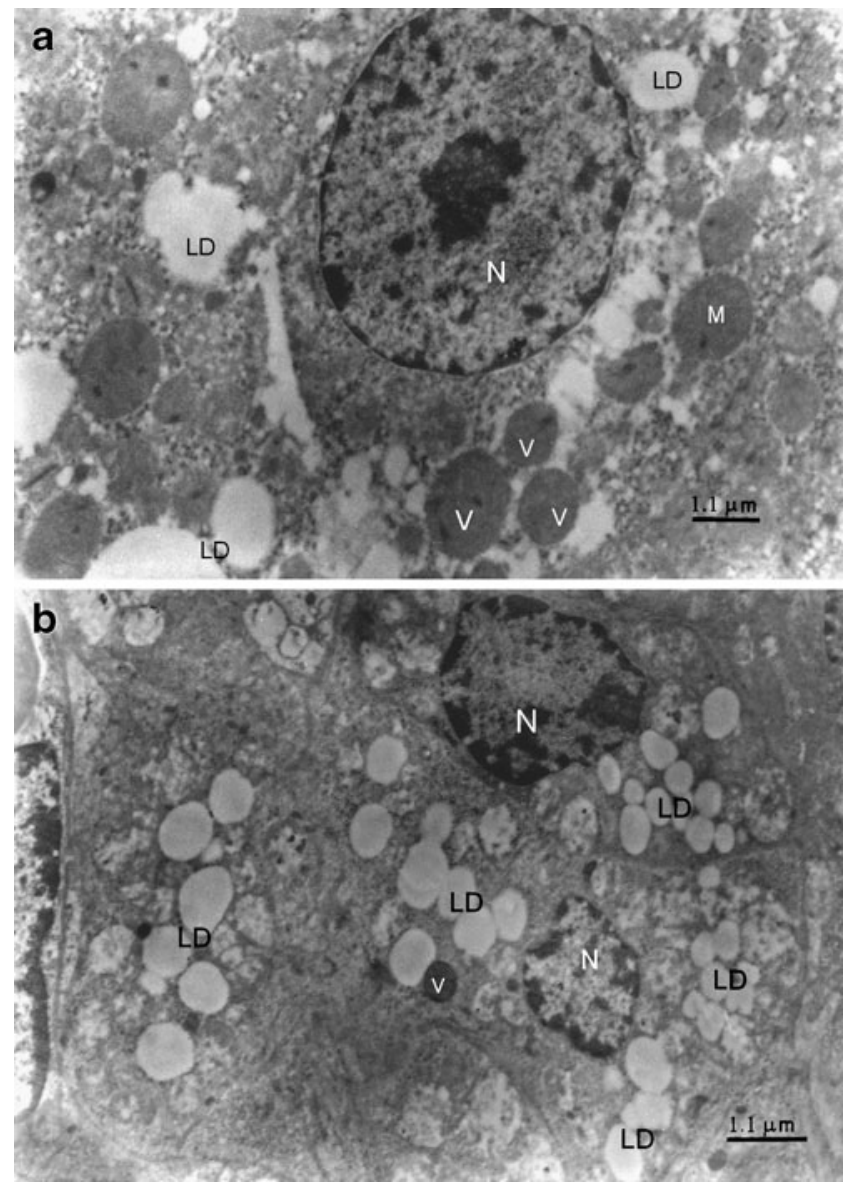

Fig. 2 Control group. Cell of adrenal cortex zona fasciculata. Magnification 10,000×. a, b Experimental group. Cell of adrenal cortex zona fasciculata. In cytoplasm there are numerous secretory vacuoles. Magnification 12,000× 
Table 1 Mean values and standard deviations of secretory vacuoles and lipid drops numbers in the zona fasciculata cells of the adrenal cortex

\begin{tabular}{|c|c|c|c|c|c|c|c|c|c|c|}
\hline \multirow[t]{2}{*}{ Group } & \multicolumn{5}{|c|}{ Secretory vacuoles } & \multicolumn{5}{|l|}{ Lipid drops } \\
\hline & $\begin{array}{l}\text { Number } \\
\text { of analyzed } \\
\text { sections }\end{array}$ & Mean & $\begin{array}{l}\text { Standard } \\
\text { deviation } \\
\text { (SD) }\end{array}$ & Minimum & Maximum & $\begin{array}{l}\text { Number } \\
\text { of analyzed } \\
\text { sections }\end{array}$ & Mean & $\begin{array}{l}\text { Standard } \\
\text { deviation } \\
\text { (SD) }\end{array}$ & Minimum & Maximum \\
\hline Control & 30 & 3.900 & 0.971 & 3.000 & 7.00 & 30 & 5.400 & 1.316 & 2.00 & 8.00 \\
\hline Experimental & 45 & 4.777 & 1.387 & 4.000 & 10.00 & 45 & 13.333 & 3.076 & 8.00 & 18.00 \\
\hline
\end{tabular}

Variance analysis $F=46.33 ; p<0.0001$

cells with cytoplasm of smaller density—especially in the apical and basal parts of the cells.

In most cells the Golgi structures occurred individually and in close vicinity of the nucleus. In a few images this structure was dispersed in the form of numerous dictyosomes. The particular parts of the Golgi apparatus showed a clear polarization of the complex. In this structure two regions could be identified - the proximal one cis and the distal one trans, in which there were large, formed vacuoles containing amorphous or granular material. Most often these were secretory granules or lysosomes. There were observed modified forms of mitochondria, characteristic of all the adrenal cortex cells, which neighboured on the endoplasmic reticulum. The mitochondria, similarly to the control group, had tubular or vesicular cristae, which resembled a honeycomb in appearance. The mitochondria matrix was electron lucent. These organelles occasionally demonstrated features of delicate swelling.

Lysosomes containing electron-dense material had a form of small structures with homogenous or granular content. Apart from primary lysosomes these organelles were also found in the form of large heterophagic vacuoles.

\section{Statistics}

The statistical analysis revealed higher mean values of secretory vacuoles and lipid drops numbers in the zona fasciculata cells of the adrenal cortex in the experimental group of animals compared with the control group (Table 1). Considerably more lipid drops were observed in the adrenal cortex cells of the animals which had received rofecoxib (Fig. 3). The analysis of variance showed statistically significant differences between the studied groups $(p<0.0001)$.

\section{Discussion}

For many years there have been conducted studies aimed at explaining of mutual relations of the hypothalamushypophysis-adrenal gland axis (Bornstein and Chrousos 1999; Belenguer-Garcia et al. 2006; Neeck 2000). The feedback mechanism is a type of regulation in which the level of produced substance affects the rate of its production.

Mutual functional relations within the hypothalamushypophysis-peripheral endocrine glands axis and feedback effects determine the synthesis and secretion of hormones on different levels. Seeking cause-effect relations between changes in morphological structure of endocrine glands incurred by exogenous substances and functioning of the axis acquires particular importance (Müller et al. 1999).

Defects in the functioning of the hypothalamus-hypophysisendocrine glands axis or dysfunctions in each of its elements can cause metabolic disorders manifesting themselves with occurrence of disease syndromes (Barraclough and Haller 1970).

Adrenocorticotropic hormone is the most important of the compounds stimulating the adrenal cortex to synthesize and release glucocorticoids, for instance, under conditions of stress.

The group of scientists (Mohn et al. 2005) managed to evaluate the mechanism of adrenocorticotropic hormone (ACTH) effects on the adrenal glands of male rats in vitro, preserving the structure of the gland. It was proved that both sodium nitroprusside (NP) - a donor of nitrogen oxide (NO) and also ACTH stimulate the secretion of cortisol. NO mediates in the acute response to $\mathrm{ACTH}$, which is

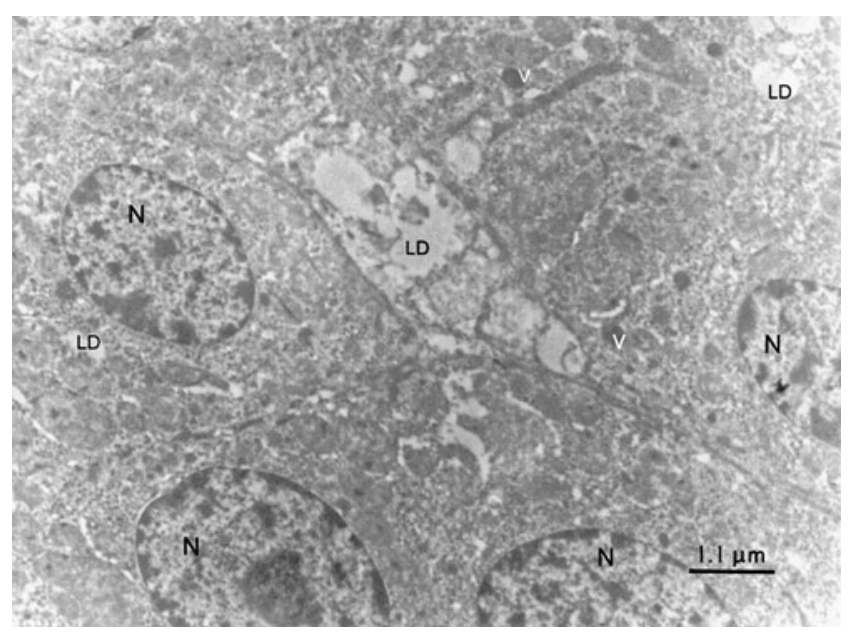

Fig. 3 Mean values of vacuoles numbers in particular groups 
confirmed by the fact that N-omega-nitro-1-arginine methyl ester-NO synthesis inhibitor, as well as hemoglobin-NO sweeper, block cortisol release in response to ACTH.

Cortisol secretion induced by ACTH or NP caused emptying of the adrenal glands of the hormone in about $40 \%$, as compared with the control adrenal glands. The mechanism of cortisol sudden release is the following: NO produced by $\mathrm{NO}$ synthesis activated by $\mathrm{ACTH}$, activates COX, under COX influence $\mathrm{PGE}_{2}$ is generated, and it causes cortisol release from secretory follicles and other organelles (Mohn et al. 2005).

Moreover, there was found a stimulating influence of exogenous $\mathrm{PGE}_{2}\left(10^{-9} \mathrm{~mol} / \mathrm{l}\right)$ on the production of aldosterone by isolated cells of the zona glomerulosa of the adrenal cortex. However, it is important to mention that in a similar way scientists managed to prove a stimulating influence of arachidonic acid $\left(5 \times 10^{-4} \mathrm{~mol} / \mathrm{l}\right)$ on the synthesis of aldosterone which was not inhibited by COX inhibitors. Arachidonic acid did not increase, and non-steroidal antiinflammatory drugs did not decrease stimulating effects of action of angiotensin II, ACTH and/or potassium ions. It was not possible to unequivocally prove (Enyedi et al. 1981) that prostaglandin production inside the adrenal glands played a significant role in the regulation of mineralocorticoids synthesis.

In recent years it has been proved (Ichitani et al. 2001), using the technique of molecular hybridization, that the expression of COX-1 and COX-2 (and specifically mRNA level for these peptides) in the kidney and adrenal gland of rats increases after the administration of pyrogenic substance (LPS). The level of mRNA for COX-2 dramatically rose $1 \mathrm{~h}$ after the administration of LPS in the renal medulla and adrenal cortex, whereas in the control group no mRNA for COX-2 was detected or its level was low. A considerable increase in COX-2 expression was also present in the adrenal medulla $6 \mathrm{~h}$ after LPS administration. No changes in the expression of COX-1 associated with the administration of pyrogenic substance were observed. COX-1 level did not show any changes after LPS administration. After LPS injection there were observed significant changes in COX-2 expression in interstitial cells of the kidney and adrenal cortex.

The activation of the hypothalamus-hypophysis-adrenal gland axis by bacterial LPS is well documented by empirical studies results, however, until today there have been doubts whether LPS has a direct effect on the adrenal gland level. Other studies (Vakharia and Hinson 2005) showed that lipopolysaccharide induces an increase in cortisol secretion from cell lines of human adrenal glands, simultaneously not affecting the release of aldosterone. LPS probably acts through specific receptors TLR2 and TLR4; as it has been proved that antagonists of these receptors (purified LPS and lipid A) stimulate basic secretion of cortisol. It is known that these receptors are responsible for the effects of LPS action in other tissues. It has also been discovered that LPS stimulates the release of prostaglandin $\mathrm{E}_{2}$ from these cells. The effect of LPS action can be neutralized by administration of non-selective COX inhibitor (indomethacin) or selective COX-2 inhibitor, however selective COX-1 inhibitors do not show such influence. For this reason, it can be concluded that the activation of COX2 and increase in $\mathrm{PGE}_{2}$ synthesis have a basic significance in the response of the adrenal glands to LPS.

The influence of interleukin (IL) on steroidogenesis (Tominaga et al. 1991) was investigated, using isolated cells of the adrenal medulla as the experimental object. It turned out that rat's IL-1 and IL-2 directly stimulate glucocorticoids synthesis in the degree that depends on the dose and duration of the experiment; ACTH has a synergistic effect on stereoidogenesis in relation to IL, however the process of stimulation requires prostaglandins co-operation (Tominaga et al. 1991).

Since interleukins can also activate the hypothalamushypophysis-adrenal gland axis (Weber et al. 1997) there were examined the effects of action of human recombined IL-3 and IL- 6 on cortisol secretion by the cells of human adrenal cortex in primary culture. IL-3 and IL-6 increased basic cortisol secretion five times. It was proved that inhibition of COX action using indomethacin completely blocks the effect of IL- 6 action and does not influence the effect of IL-3 action.

The subject of the study (Bugajski et al. 1996) was the role of prostaglandins in the stimulation of the hypothalamus-hypophysis-adrenal gland axis by adrenergic antagonists and catecholamines in rats which did not undergo anesthesia. Indomethacin (non-selective, irreversible COX inhibitor) was administered regularly to cerebral ventricles (i.c.v.) 15 min before administration of: phenylephrine, clonidine, or isoproterenol. Indomethacin almost completely neutralized the increase in corticosterone level caused by phenylephrine, significantly reduced the effect of clonidine action and had no influence on the effect of isoproterenol action.

The subject of the study was the effect of interleukin on steroidogenesis (Tominaga et al. 1991), using isolated adrenal medulla cells as the experimental object. It turned out that rat's IL-1 and IL-2 directly stimulate glucocorticoids synthesis in the degree that depends on the dose and duration of the experiment; ACTH has a synergistic effect on stereoidogenesis in relation to IL, however the process of stimulation requires prostaglandins co-operation.

The adrenal medulla receives blood which is extremely rich in glucocorticoids through branches of coronary arterioles. Moreover, in the adrenal medulla venous vessels there are bundles of smooth myocytes located under the endothelium along the long axis of the vessel, which enable 
retention of blood and thus prolong the contact of the medulla cells with the cortex hormones (Brophy et al. 2007).

That has a considerable significance for glucocorticoids' regulating effect on adrenalin production. Also chromaffin cells have a strong effect on adrenal cortex cells. In a mixed culture stereoidogenesis was ten times higher than the synthesis of these hormones in cortex cells culture (Haidan et al. 1998). The results of experimental studies univocally indicate a strong and mutual functional dependence of the adrenal cortex and medulla, facilitated by specific vascularization.

At present there are conducted studies on the possibility of the application of coxibs in the therapy of neoplastic and neurodegenerative diseases (Kim et al. 2004). It has been proved that rofecoxib inhibits processes of degeneration of cholinergic neurons in vivo, however the initial results of studies on the effectiveness of rofecoxib in treating benign and moderate forms of Alzheimer's disease have not shown the possibility of inhibiting of the loss of cognitive abilities during 12 months of the drug use (Rogers et al. 1993; Stewart et al. 1997; Hawkey 1999; Pasinetti and Aisen 1998; Aisen et al. 2003; Reines et al. 2004). It has been proved, however, that celecoxib alleviates positive and negative effects of schizophrenia, most probably through a different mechanism than inhibiting of COX-2 (Yokota et al. 2004).

The withdrawing of Vioxx drug from sale did not mean resignation from the therapy using coxibs (Cahana and Mauron 2006). Celecoxib, which showed a considerably smaller prothrombotic action in the trials than rofecoxib, is still a popular drug, also in Poland. In addition, in western markets there are also present valdecoxib, parecoxib, lumiracoxib, and in the phase of studies there are next coxibs-e.g., tiracoxib, tilmacoxib, firocoxib, cimicoxib (Thomas 2006). These drugs differ in chemical structure and consequently action, and still require detailed studies. Rofecoxib itself is still being examined in view of possible application in dementia, neurodegenerative and neoplastic diseases (Kawamori et al. 1998; Watson 1998; Steinbach et al. 2000; Salmenkivi et al. 2001; Herendeen and Lindley 2003; Zatelli et al. 2005; Harris et al. 2006, 2007); so it is possible that it will return - in a different character-as a lifesaving or life-prolonging drug. In such a case, the potential benefits may outweigh the risks, since drug toxicity is a relative issue (Dickman and Ellershaw 2004; Mamadani et al. 2004; Krumholz et al. 2008).

A very good overview of risks posed by using NSAIDs as well as the ways of preventing complications caused by such drugs was presented in 2001 by Laine (2001).

Very interesting results showing the response of the adrenal gland to the chemical stimulus were obtained in the studies on the chronic toxicity of Chlorpyrifos-methyl performed on experimental animals. In the rats of Fisher strain used in the experiment there was discovered vacuolization of the zona fasciculata of the adrenal glands, which was statistically significant (Clegg 1992).

In the 1980s, a group of Swedish scientists (Lund et al. 1988) investigated the effects of DDT metabolites. Labeled 14C 3-methylsulphonyl-DDE (3-MeSO2-DDE) was administered to C57BL female mice. By means of autoradiography the authors showed a large accumulation of the chemical compound in the adrenal cortex. The histopathological examination of the adrenal glands conducted 12 days after the administration of the single dose of 3-methylsulphonyl-DDE (3-MeSO2-DDE) revealed the considerable vacuolization and necrosis of the zona fasciculata. The authors conclude that the administered substance activates the adrenal glands metabolism and simultaneously causes serious selective degenerative changes in the areas of the adrenal cortex.

A highly useful character of cell cultures from the zona fasciculata of the adrenal cortex of guinea-pigs, dogs and monkeys was proved in the experiment using three substances toxic to the adrenal glands: PD 132301-2, 1(O-chlorophenyl)-1-( $p$-chloro-phenyl)-2, 2-dichloroethane (o, p'-DDD), and aminoglutethimide (AG). Those cell cultures were tested in vitro, neutral red (NR) was used as the marker of cell viability and cortisol production (Grushenka et al. 1994).

It was proved that lipid drops with homogenous electron lucent matrix dominated in the cells characterized by high intensity of steroidogenesis, whereas lipid drops with electron-dense matrix were most often found in the cells with low intensity of steroidogenesis. The use of ionophore A23187 and/or ACTH resulted in a decrease in the lipid drops diameter and a simultaneous increase in their number in the cell cytoplasm. The authors suggest that the ultrastructure of lipid drops depends on the changes in calcium ion concentration in the cytoplasm. The processes that cause changes in the ultrastructure of lipid drops are probably correlated with steroidogenesis (Tokar et al. 2004).

Roughneen et al. (1989) studied the effect of cholestasis which was experimentally induced in rats on the structure and function of the zona fasciculata. The ultrastructural studies showed excessive accumulation of vesicles containing biogenic precursors of glucocorticosteroids. Cholestasis proved to cause an intensive metabolic activity of the zona fasciculata of the adrenal cortex.

The aim of the study of another group of scientists observing changes which take place in the adrenal glands under the influence of exogenous substances was to investigate the interactions which occur between polychlorinated biphenyls (Clophen A60) and diethyl phthalate (DEP) in their effects on the adrenal and thyroid glands from male and female rats of Wistar strain. Vacuolations and degenerative changes were found in the rats' adrenal cortex zona fasciculata. It was established that the simul- 
taneous administration of Clophen A60 and DEP intensifies the toxic effect of these chemical compounds on the adrenal glands of the experimental animals (Pereira et al. 2007).

The analysis of adrenal cortex tissue electronograms conducted in this study, revealed that in the area of zona fasciculata cells the amount of smooth endoplasmic reticulum increases, and its canals are clearly dilated. The dilation of the smooth endoplasmic reticulum (SER) is also one of morphological signs of biochemical changes occurring in the cell, which was also observed in our study. There was observed a greater number of secretory vacuoles and large lipid drops containing cholesterol, other types of lipids and generated glucocorticoids in the cytoplasm with prominent smooth endoplasmic reticulum. Follicles were separating from SER membranes and initiated the formation of vacuoles. There were also found cells with cytoplasm of smaller density - especially in the apical and basal parts of the cells (Okada et al. 2003).

The cellular structures which are very sensitive to the effect of active oxygen forms include the mitochondria, since approximately $90 \%$ oxygen is metabolized in these organelles. Mitochondria occasionally demonstrated features of delicate swelling, which should be noted as a change in the functional condition of the cell.

To sum up the study results, there may be suggested a possible influence of rofecoxib on the ultrastructure of zona fasciculata cells of the adrenal cortex.

The changes observed in this study, which occurred on the cellular level with the application of large doses of the drug, result from the activation of intracellular metabolic processes, they may also be the effect of the mobilization of the organism's adaptation mechanisms. Explaining of the nature of the observed ultrastructural changes requires including of molecular biology methods into studies, and also monitoring of the endocrine function of the adrenal gland during experiments.

Conflict of interest The authors declare that they have no conflict of interest.

Open Access This article is distributed under the terms of the Creative Commons Attribution Noncommercial License which permits any noncommercial use, distribution, and reproduction in any medium, provided the original author(s) and source are credited.

\section{References}

Aisen PS, Schafer KA, Grundman M, Pfeiffer E, Sano M, Davis KL, Farlow MR, Jin S, Thomas RG, Thal LJ (2003) Effects of rofecoxib or naproxen vs placebo on Alzheimer disease progression: a randomized controlled trial. JAMA 289:2819-2826
Bakhle YS (1999) Structure of COX-1 and COX-2 enzymes and their interaction with inhibitors. Drugs Today 35:237

Barraclough CA, Haller EW (1970) Positive and negative feedback effects of estrogen on pituitary LH synthesis and release in normal and androgen-sterilized female rats. Endocrinology 86:542-551

Belenguer-Garcia S, Oliver C, Morméde P (2006) Facilitation and feedback in the hypothalamo-pituitary-adrenal axis during food restriction in rats. J Neurol 5:663-668

Bombardier C, Laine L, Reicin A, Shapiro D, Burgos-Vargas R, Davis B, Ph D, Day R, Bosi Ferraz M, Hawkey CJ, Hochberg MC, Kvien TK, Schnitzer TJ (2000) Comparison of upper gastrointestinal toxicity of rofecoxib and naproxen in patients with rheumatoid arthritis. N Engl J Med 343:1520-1528

Bornstein SR, Chrousos GP (1999) Adrenocorticotropin (ACTH) and non-ACTH-mediated regulation of the adrenal cortex: neural and immune inputs. J Clin Endocrinol Metab 84:1729-1736

Brophy IM, Levesque LE, Zhang B (2007) The coronary risk of cyclooxygenase- 2 inhibitors in patients with a previous myocardial infarction. Heart 93:189-194

Bugajski J, Gadek-Michalska A, Borycz J, Radosz GR, Bugajski A (1996) Effect of indomethacin on the pituitary-adrenocortical response to adrenergic stimulation. Life Sci 59:1157-1164

Cahana A, Mauron A (2006) The story of VIOXX - no pain and a lot of gain: ethical concerns regarding conduct of the pharmaceutical industry. J Anaesth 20:348-351

Clegg DJ (1992) Pesticide residues in food. Chlorpyrifos-methyl. First draft prepared by Carp, Ontario

Connel NA, Kumar A, Chatzipanteli K, Mohan A, Agarwal RK, Head C, Bornstein SR, Abou-Samra AB, Gwosdow AR (1994) Interleukin-1 regulates corticosterone secretion from the rat adrenal gland through a catecholamine-dependent and prostaglandin E2-independent mechanism. Endocrinology 135: 460-467

Courtney P, Doherty M (2002) Key questions concerning paracetamol and NSAIDs for osteoarthritis. Ann Rheum Dis 61:767-773

Crofford LJ (2001) Rational use of analgesic and antiinflammatory drugs. NEJM 345:1844-1846

Dannhardt G, Kiefer W (2001) Cyklooxygenase inhibitors-current status and future prospects. Eur J Med Chem 36:109-126

Dickman A, Ellershaw J (2004) For discussion NSAIDs: gastroprotection or selective COX-2 inhibitor? Palliat Med 18:275-286

Ehrich EW, Dallob A, De Lepeleire I (1999) Characterization of rofecoxib as a cyclooxygenase-2 isoform inhibitor and demonstration of analgesia in the dental pain model. Clin Pharmacol Ther 65:336-347

Fletcher JT, Graf N, Scarman A, Saleh H, Alexander SJ (2006) Nephrotoxicity with cyclooxygenase-2 inhibitor use in children. Pediatr Nephrol 21:1893-1897

Fu JY, Masferrer JL, Seibert K, Raz A, Needleman P (1990) The induction and supression of prostaglandin $\mathrm{H} 2$ synthase (cyclooxygenase) in human monocytes. J Biol Chem 256:16737-16740

Gierse JK, Koboldt CM, Walker MC, Seibert K, Isakson PC (1996) A single amino acid difference between cyclooxygenase-1 (COX-1) and $-2(\mathrm{COX}-2)$ reverses the selectivity of COX-2 specific inhibitors. J Biol Chem 271:15810-15814

Głuszko P (2004) Krótka historia Vioxxu. Med Prakt 10:186-188

Grushenka HI, Vernetti LA, Macdonald JR (1994) Isolation and use of primary adrenocortical cells from guinea pigs, dogs and monkeys forin vitro toxicity studies. Toxicol Mech Met 1537-6524: $149-160$

Haag MDM, Bos MJ, Hofman A, Koudstaal PJ, Breteler MMB, Stricker BHC (2008) Cyclooxygenase selectivity of nonsteroidal anti-inflammatory drugs and risk of stroke. Arch Intern Med 168:1219-1224

Haidan A, Bornstein SR, Glasow A, Uhlmann K, Lübke C, EhrhartBornstein M (1998) Basal steroidogenic activity of adrenocortical 
cells is increased 10 -fold by coculture with chromaffin cells. Endocrinology 139:772-780

Harris RE, Beebe-Donk J, Alshafie GA (2006) Reduction in the risk of human breast cancer by selective cyclooxygenase-2 (COX-2) inhibitors. BMC Cancer 6:27

Harris RE, Beebe-Donk J, Alshafie GA (2007) Reduced risk of human lung cancer by selective cyclooxygenase 2 (COX-2) blockade: results of a case control study. Int J Biol Sci 3:328-334

Hawkey CJ (1999) COX-2 inhibitors. Lancet 353:307-314

Hellstrom HR (2007) A proposed fairer method for conducting rofecoxib trials. Med Hypotheses 67:1261-1266

Herendeen JM, Lindley C (2003) Use of NSAIDs for the chemoprevention of colorectal cancer. Ann Pharmacother 37:1664-1674

Huang SHK (2000) Rheumatology: 7. Basics Therapy CMAJ $163: 417-423$

Ichitani Y, Holmberg K, Maunsbach AB, Haeggström JZ, Samuelsson B, De Witt D, Hökfelt T (2001) Cyclooxygenase-1 and cyclooxygenase-2 expression in rat kidney and adrenal gland after stimulation with systemic lipopolysaccharide: in situ hybridization and immunocytochemical studies. Cell Tissue Res 303:235-252

Kawamori T, Lubet R, Steele VE, Kelloff GJ, Kaskey RB, Rao CV, Reddy BS (1998) Chemopreventative activity of celecoxib, a specific cyclooxygenase-2 inhibitor, against colon carcenogenesis. Cancer Res 58:409-412

Kim PS, Reicin AS, Villalba L, Witter J, Wolfe MM, Topol EJ (2004) Rofecoxib, Merck, and the FDA. NEJM 351:2875-2878

Krumholz HM, Hines HH, Ross JS S, Presler AH, Egilman DS (2008) What have we learnt from VIOXX? BMJ 334:120-123

Langman MJ, Jensen DM, Watson DJ, Harper SE, Zhao PL, Quan H, Bolognese JA, Simon TJ (1999) Adverse upper gastrointestinal effects of rofecoxib compared with NSAIDs. JAMA 282:1929 1933

Lenzer J (2005) FDA advisers warn: COX 2 inhibitors increase risk of heart attack and stroke. BMJ 330:440

Lipsky PE, Brooks P, Crofford LJ, DuBois R, Graham D, Simon LS, van de Putte LB, Abramson SB (2000) Unresolved issues in the role of cyclooxygenase-2 in normal physiologic processes and disease. Arch Int Med 160:913-920

Lund BO, Bergman A, Brandt I (1988) Metabolic activation and toxicity of a DDT-metabolite, 3-methylsulphonyl-DDE, in the adrenal zona fasciculata in mice. Chem Biol Interact 65:2540

Luo Ch, He M, Bohlin L (2005) Is COX-2 a perpetrator or a protector? Selective COX-2 inhibitors remain controversial. Acta Pharmacol Sin 26:926-933

Mamadani M, Juurlink DN, Lee DS, Rochon PA, Kopp A, Naglie G, Austin PC, Laupacis A, Stukel TA (2004) Cycoloxygenase-2 inhibitors versus non-selective nonsteroidal anti-inflammatory drugs and congestive heart failure outcomes in elderly patients: a population-based kohort study. Lancet 365:1751-1756

Malmstrom K, Fricke JR, Kotey P, Kress B, Morrison B (1999) A comparison of rofecoxib and celecoxib, two cyclooxygenase-2 inhibitors, in postoperative dental pain: a randomized, placeboand active-comparator-controlled clinical trial. Clin Ther 21: $1653-1663$

Mandell BF (1999) General tolerability and use of nonsteroidal antiinflammatory drugs. Am J Med 107:72-77

Masferrer JL, Zweifel BS, Seibert K, Needleman P (1990) Selective regulation of cellular cyclooxygenase by dexamethasone and endotoxin in mice. J Clin Invest 86:1375-1379

Mohn CE, Fernardez-Solari J, De Lavrentis A, Prestifilippo JP, De la Cal C, Funk R, Bornstein SR, McCann SM, Rettori V (2005) The rapid release of corticosterone from the adrenal induced by $\mathrm{ACH}$ is mediated by nitric oxide acting by prostaglandin E2. Proc Natl Acad Sci USA 102:6213-6218
Müller EE, Locatelli V, Cocchi D (1999) Neuroendocrine control of growth hormone secretion. Physiol Rev 79:511-607

Neeck G (2000) Neuroendocrine and hormonal perturbations and relations to the serotonergic system in fibromyalgia patients. Scand J Rheumatol 29:8-12

Needleman P, Manning PT (1999) Interactions between the inducible cyclooxygenase (COX-2) and nitric oxide synthase (iNOS) pathways: implications for therapeutic intervention in osteoarthritis. Osteoarthritis Cartilage 7:367-370

Okada S, Murakami Y, Yokotani K (2003) Role of brain thromboxane A2 in the release of noradrenaline and adrenaline from adrenal medulla in rats. Eur J Pharmacol 467:125-131

Ong CKS, Lirk P, Tan CH, Seymour RA (2007) An evidence-based update on nonsteroidal anti-inflammatory drugs. Clin Med Res 5:19-34

Pasinetti GM, Aisen PS (1998) Cyclooxygenase-2 expression is increased in frontal cortex of Alzheimers disease brain. Neuroscience 87:319-324

Pereira C, Mapuskar K, Rao V (2007) A two-generation chronic mixture toxicity study of Clophen A60 and diethyl phthalate on histology of adrenal cortex and thyroid of rats. Acta Histochem 109:29-36

Price-Forbes AN, Callaghan R, Allen ME, Rowe IF (2005) A regional audit of the use of COX-2 selective non-steroidal antiinflammatory drugs (NSAIDs) in rheumatology clinics in the West Midlands, in relation to NICE guidelines. Rheumatology 44:921-924

Ramirez-Alcantara V, LoGuidic A, Boelsterli UA (2009) Protection from diclofenac-induced small intestinal injury by the JNK inhibitor SP600125 in a mouse model of NSAID-associated enteropathy. Am J Physiol Gastrointest Liver Physiol 297:990 998

Reines SA, Block GA, Morris JC, Liu G, Nessly ML, Lines CR, Norman BA, Baranak CC (2004) Rofecoxib: no effect on Alzheimer's disease in a 1-year, randomized, blinded, controlled study. Neurology 62:66-71

Reynolds ES (1963) The use of lead citrate of high ph as an electronopaque stain in electron microscopy. J Cell Biol 17:208-212

Rogers J, Kirby LC, Hempelman SR, Berry DL, McGeer PL, Kaszniak AW, Zalinski J, Cofield M, Mansukhani L, Willson P, Kogan F (1993) Clinical trial of indomethacin in Alzheimer's disease. Neurology 43:1609-1611

Roughneen PT, Tallon KM, Russell DH, Roughneen PT, Tallon KM, Rowlands BJ (1989) Structural and functional alterations in the zona fasciculata of the rat adrenal cortex in obstructive jaundice. Surg HPB 1:271-281

Roumie CL, Mitchel EF Jr, Kaltenbach L, Arbogast PG, Gideon P, Griffin MR (2008) Nonaspirin NSAIDs, cyclooxygenase 2 inhibitors, and the risk for stroke. Stroke 39:2037-2045

Salmenkivi K, Haglund C, Ristimäki A, Arola J, Heikkilä P (2001) Increased expression of cyclooxygenase-2 in malignant pheochromocytomas. J Clin Endocrinol Metab 86:5615-5619

Scali C, Giovannini MG, Prosperi C, Bellucci A, Pepeu G, Casamenti F (2003) The selective cyclooxygenase-2 inhibitor rofecoxib suppresses brain inflammation and protects cholinergic neurons from excitotoxic degeneration in vivo. Neuroscience 117:909919

Steinbach G, Lynch PM, Phillips RKS (2000) The effect of celecoxib, a cyclooxygenase- 2 inhibitor, in familial adenomatous polyposis. NEJM 342:1946-1952

Simmons DL, Levy DB, Yannoni Y, Erikson RL (1989) Identification of a phorbol ester-repressible v-src-inducible gene. Proc Natl Acad Sci USA 86:1178-1182

Simmons DL, Botting RM, Hla T (2004) Cyclooxygenase isozymes: the biology of prostaglandin synthesis and inhibition. Pharmacol Rev 56:387-437 
Spiegel BMR, Targownik L, Dulai GS, Gralnek IM (2003) The cost-effectiveness of cyclooxygenase-2 selective inhibitors in the management of chronic arthritis. Ann Intern Med 138: 795-806

Stewart WF, Kawas C, Corrada M, Metter EJ (1997) Risk of Alzheimer's disease and duration of NSAID use. Neurology 48:626-632

Thomas WJ (2006) The vioxx story: would it have ended differently in the European Union? J Law Med 32:365-380

Tokar SL, Koval LM, Javorska OM, Lukianets OO (2004) Ultrastructural characteristics of lipid droplets in rat adrenocortical cells from zona fasciculata-reticularis. Physiol J (Kiev) 50:107-113

Tominaga T, Fukata J, Naito Y, Usui T, Murakami N, Fukushima M, Nakai Y, Hirai Y, Imura H (1991) Prostaglandin-dependent in vitro stimulation of adrenocortical steroidogenesis by interleukins. Endocrinology 128:526-531

Vakharia K, Hinson JP (2005) Lipopolysaccharide directly stimulates cortisol secretion by human adrenal cells by a cyclooxygenasedependent mechanism. Endocrinology 146:1398-1402

Vane JR, Flower RJ, Botting RM (1990) History of aspirin and its mechanism of action. Stroke 21:12-23

Wadman M (2007) The pain game. Nature 448:400-401
Warner TD, Mitchell JA (2004) Cyclooxygenases: new forms, new inhibitors, and lessons for the clinic. FASEB J 18:790-804

Watson AJ (1998) Chemopreventive effects of NSAIDs against colorectal cancer: regulation of apoptosis and mitosis by COX-1 and COX-2. Hist Histopathol 113:591-597

Weber MM, Michl P, Auernhammer CJ, Engelhardt D (1997) Interleukin-3 and interleukin-6 stimulate cortisol secretion from adult human adrenocortical cells. Endocrinology 138:2207-2210

Whittle BJ (2000) COX-1 and COX-2 products in the gut: therapeutic impact of COX-2 inhibitors. Gut 47:320-325

Yokota O, Terada S, Ishihara T, Nakashima H, Kugo A, Ujike H, Tsuchiya K, Ikeda K, Saito Y, Murayama S, Ishizu H, Kuroda S (2004) Neuronal expression of cyclooxygenase-2, a proinflammatory protein, in the hippocampus of patients with schizophrenia. Prog Neuropsychopharmacol Biol Psychiatry 28:715-721

Zarraga E, Schwarz ER (2007) Coxibs and heart disease. What we have learned and what else we need to know. J Am Coll Cardiol 49:1-14

Zatelli MC, Luchin A, Piccin D, Tagliati F, Bottoni A, Vignali C, Bondanelli M, Uberti EC (2005) Cyclooxygenase-2 inhibitors reverse chemoresistance phenotype in medullary thyroid carcinoma by a permeability glycoprotein-mediated mechanism. J Clin Endocrinol Metab 90:5754-5760 